\title{
HUBUNGAN DURASI DUDUK DENGAN NYERI PUNGGUNG BAWAH PADA PERAWAT RUMAH SAKIT ATMA JAYA JAKARTA, INDONESIA
}

\author{
Fanuel Utama ${ }^{1}$, Robby Irawan ${ }^{2}$, Jimmy Barus ${ }^{1}$, Stefanie Agustine ${ }^{3}$
}

${ }^{1}$ Departemen Neurologi, FKIK Unika Atma Jaya, Jakarta, Indonesia

${ }^{2}$ Departemen Anatomi, FKIK Unika Atma Jaya, Jakarta, Indonesia

${ }^{3}$ Departemen IImu Kesehatan Masyarakat, FKIK Unika Atma Jaya, Jakarta, Indonesia

Diterima 21 Juli 2018

Disetujui 04 September 2018

Publikasi 21 September 2018

Korespondensi: fanuelutama@yahoo.com
Cara merujuk artikel ini: Utama (et al). 2018. Hubungan durasi duduk dengan nyeri punggung bawah pada perawat rumah sakit atma jaya Jakarta, indonesia Callosum Neurology Journal 1(3): 103-107. DOI: 10.29342/cnj.v1i3.35

\section{ABSTRAK}

Latar Belakang: Nyeri punggung bawah (NPB) pernah diderita oleh $24,7 \%$ dari seluruh pekerja di Indonesia pada tahun 2013. Prevalensi NPB pada perawat ditemukan sebesar $84,2 \%$.

Tujuan: Untuk mengetahui pengaruh durasi duduk terhadap NPB perawat di Rumah Sakit Atma Jaya.

Metode Penelitian: Penelitian analitik kuantitatif dengan desain penelitian potong lintang. Jumlah sampel sebanyak 131 perawat Rumah Sakit Atma Jaya, diambil menggunakan metode total sampling. Penelitian dilakukan sejak bulan Januari-Mei 2017.
Hasil: Sebanyak 40 (30,5\%) perawat ditemukan mengalami NPB dalam 12 bulan terakhir. Didapatkan durasi duduk berhubungan dengan NPB $(p<0,001)$. Hasil analisis untuk jenis kelamin ditemukan tidak bermakna $(p=0,211)$.

Simpulan: Durasi duduk merupakan salah satu faktor risiko terjadinya NPB. Intervensi lebih lanjut dibutuhkan untuk mengurangi probabilitas terjadinya NPB.

Kata Kunci: Nyeri Punggung Bawah, Penyakit terkait Kerja, Perawat, Durasi Duduk Lama

\section{ABSTRACT}

Background: Low back pain (LBP) had been suffered by $24,7 \%$ of the entire Indonesian worker in 2013.

Purpose: The purpose of this study is to determine relation between sitting duration and low back pain of nurse in Atma Jaya Hospital.

Method: Quantitative analitic study with cross sectional design. There were 131 Atma Jaya Hospital nurses selected by total sampling. This study was conducted from Januari until May 2017
Result: 40 (30,5\%) nurses has been suffering LBP in the last 12 month. The analysis showed sitting duration is related to $\operatorname{LBP}(p<0,001)$. The result of analysis showed that sex is not related to $\operatorname{LBP}(p=0,211)$.

Conclusion: Prolonged sitting is one of the risk factor of LBP. Intervention has to be done to decrease the probability of LBP occurence. Keywords: Low Back Pain, Occupational Disease, Nurse, Prolonged Sitting 


\section{Latar Belakang}

Sekitar $75-80 \%$ dari seluruh populasi di dunia pernah mengalami nyeri punggung bawah (NPB) setidaknya sekali dalam hidupnya. ${ }^{1}$ Kondisi NPB merupakan salah satu penyakit kerja yang dialami oleh $24,7 \%$ dari seluruh pekerja di Indonesia pada tahun 2013. ${ }^{2} \quad$ Sebanyak 32\% pekerja membutuhkan waktu absen sampai satu bulan agar nyeri tersebut tidak menjadi semakin berat dan membuat absen kerja yang lebih lama. ${ }^{3}$ Kondisi NPB menjadi alasan tidak masuk kerja paling sering di Inggris. Waktu kerja terbuang akibat hal ini dapat mencapai 3,5 juta hari per tahunnya.

Pekerja kesehatan merupakan salah satu pekerja yang berisiko menderita NPB. Hasil penelitian di Turki menyatakan bahwa pekerja kesehatan merupakan kelompok pekerja yang paling berisiko menderita NPB. Hal ini disebabkan oleh pekerjaan yang dilakukan oleh pekerja kesehatan seperti stress akibat pekerjaan, berdiri dalam jangka waktu yang lama atau mengangkat pasien. ${ }^{5}$ Perawat merupakan tenaga kesehatan yang dilaporkan paling banyak menderita NPB dibandingkan kelompok lainnya menurut studi di Jepang, Taiwan, dan Turki. ${ }^{5-7}$ Sebuah penelitan di Srilanka menemukan bahwa seorang perawat menderita NPB setidaknya sebulan sekali. 8 Prevalensi NPB pada perawat di Turki dapat mencapai lebih dari $80 \%{ }^{9}$ Salah satu faktor risiko NPB adalah duduk lama, ${ }^{10,11}$ sedangkan duduk merupakan aktivitas utama dari pekerja berkerah biru. Pekerja yang melakukan tugas administratif membutuhkan duduk sepanjang waktu kerjanya. Sebuah penelitian di Denmark juga menyatakan bahwa duduk lama memengaruhi NPB secara bermakna. $^{12}$

Perawat melakukan banyak kegiatan sepanjang waktu kerjanya. Tugas administratif juga merupakan salah satu aktivitas utama yang dilakukannya, yang tentunya membutuhkan duduk. Penelitian lain di Taiwan menyatakan bahwa perawat menderita NPB dikarenakan duduk lama. ${ }^{13} \quad$ Minimnya jumlah penelitian yang dilakukan untuk mengetahui duduk sebagai faktor risiko NPB membuat peneliti tertarik untuk melakukan penelitian ini. Tujuan dari penelitian ini adalah untuk mengetahui pengaruh durasi duduk terhadap kejadian NPB pada perawat di Rumah Sakit Atma Jaya, Jakarta.

\section{Metode Penelitian}

Penelitian ini dimulai sejak bulan Januari-Mei 2017. Metode penelitian yang digunakan adalah penelitian analitik kuantitatif dengan desain penelitian potong lintang. Sampel yang diambil merupakan seluruh perawat yang bekerja sepenuh waktu di Rumah Sakit Atma Jaya, Jakarta Utara. Kriteria inklusi pada penelitian ini adalah responden bekerja sebagai perawat Rumah Sakit Atma Jaya sepenuh waktu dengan usia $\leq 59$ tahun. Kriteria eksklusi pada penelitian ini adalah apabila responden menolak untuk berpartisipasi dalam penelitian, sedang hamil, mempunyai riwayat atau sedang mengalami trauma dan penyakit pada punggung bawah (spondilosis, spondilitis, dII), mengalami penyakit organ dalam seperti penyakit gastrointestinal, penyakit ginjal, dan penyakit organ pada pelvis, dan responden memiliki pekerjaan tambahan. Sebanyak 131 subjek penelitian telah dipilih dengan menggunakan metode total sampling. Durasi duduk dibagi menjadi lama ( $\geq 4$ jam) dan sebentar ( $<4$ jam). Seluruh responden telah diminta persetujuannya untuk diikutsertakan dalam penelitian dengan informed consent tertulis. Analisis data univariat digunakan untuk data karakteristik dasar. Analisis chi-square digunakan untuk mengetahui hubungan lama duduk, jenis kelamin dan obesitas terhadap NPB. Pengujian hipotesis menggunakan two-tail test. Jika $p$-value lebih dari nilai signifikansi $(0,05)$, maka hipotesis nol diterima. Pengolahan data dengan menggunakan program pengolah data.

\section{Hasil Penelitian}

Sebanyak 131 perawat dipilih menjadi responden penelitian. Karakteristik dasar dari sampel yang memenuhi kriteria inklusi dan eksklusi ( $N=131)$ dijabarkan pada tabel 1. Perawat yang duduk dengan durasi lama berjumlah $40(30,5 \%)$ dan durasi duduk sebentar 91 (69,5\%).

Pada tabel 2 dijabarkan bahwa sebanyak 40 perawat mengalami NPB dengan 18 (45\%) diantaranya duduk dengan durasi sebentar dan 22 (55\%) perawat duduk dengan durasi lama. Sedangkan 91 perawat lainnya tidak mengalami NPB dengan $73(80,2 \%)$ duduk dengan durasi sebentar dan 18 (19,8\%) duduk dengan durasi lama. Didapatkan perbedaan yang bermakna antara kedua kelompok dengan nilai $p<0,001$.

Tabel 1. Karakteristik dasar perawat di Rumah Sakit Atma Jaya, Jakarta ( $n=131)$

Variabel $\mathrm{n}(\%)$ 


\begin{tabular}{ll}
\hline $\begin{array}{l}\text { Jenis kelamin } \\
\text { Laki-laki }\end{array}$ & $23(17,6)$ \\
$\begin{array}{l}\text { Perempuan } \\
\text { Obesitas }\end{array}$ & $108(82,4)$ \\
Ya & $21(16,0)$ \\
Tidak & $110(84,0)$ \\
Durasi duduk selama bekerja \\
< 4jam
\end{tabular}

Selain itu dilakukan analisis untuk mengetahui faktor risiko lain seperti jenis kelamin dan obesitas. Empat perawat laki-laki mengalami NPB dan 19 perawat lainnya tidak mengalaminya, sedangkan 36 perawat perempuan mengalami NPB dan 72 perawat lainnya tidak mengalami NPB. Hasil analisis menunjukkan bahwa jenis kelamin tidak berhubungan dengan NPB dengan nilai $p=0,211$. Hasil analisis untuk obesitas juga tidak bermakna terhadap kejadian NPB dengan nilai $p=0,443$. Obesitas didapatkan pada 21 perawat, delapan (20\%) diantaranya mengalami NPB, dan dari 110 perawat yang tidak obesitas, 32 (80\%) diantaranya mengalami NPB. Nilai p pada jenis kelamin dan obesitas menunjukkan bahwa tidak adanya perbedaan yang signifikan pada perawat yang mengalami NPB dan yang tidak.

\section{Pembahasan}

Sebanyak 40 (30,5\%) perawat pernah mengalami NPB dalam 12 bulan terakhir. Proporsi ini cukup rendah jika dibanding beberapa penelitian yang ditemukan lebih dari 70\% (Nigeria: 73,53\%; Nigeria dan Etiopia: 70,87\%; Turki: 84,2\%.9,14,15 Beberapa penelitian lain melaporkan prevalensi NPB yang juga rendah, seperti penelitian di Iran $(29,9 \%)$ yang mirip dengan prevalensi NPB di beberapa negara maju seperti di Inggris, Perancis, dan Amerika Serikat. ${ }^{7}$ Under reporting juga dapat terjadi oleh karena perawat menganggap NPB sebagai risiko pekerjaan sehingga perawat tidak melaporkan NPB yang dialaminya. ${ }^{16}$ Absen kerja merupakan dampak yang paling sering terjadi dari NPB. Dilaporkan 58\% perawat tidak masuk kerja/ absen selama 1-7 hari pertahun bahkan $16 \%$ perawat dapat absen kerja sampai 30 hari per tahun karena NPB. ${ }^{17}$ Kondisi NPB kronis juga dapat menurunkan kemampuan seseorang memenuhi fungsi sosialnya dan dapat berujung pada depresi. 18

Tabel 2. Faktor yang memengaruhi nyeri punggung bawah perawat di Rumah Sakit Atma Jaya, Jakarta

\begin{tabular}{|c|c|c|c|}
\hline \multirow{2}{*}{ Variabel } & NPB & Tidak NPB & \multirow[b]{2}{*}{$p$} \\
\hline & n (\%) & $\mathrm{n}(\%)$ & \\
\hline \multicolumn{4}{|l|}{$\begin{array}{l}\text { Jenis } \\
\text { kelamin }\end{array}$} \\
\hline Laki-laki & 4 (10) & $19(20,9)$ & 0,211 \\
\hline Perempuan & $36(90)$ & $72(79,1)$ & \\
\hline \multicolumn{4}{|l|}{$\begin{array}{l}\text { Durasi } \\
\text { duduk } \\
\text { selama } \\
\text { bekerja }\end{array}$} \\
\hline$<4$ jam & $18(45)$ & $73(80,2)$ & $0,001 *$ \\
\hline$\geq 4$ jam & 22 (55) & $18(19,8)$ & \\
\hline \multicolumn{4}{|l|}{ Obesitas } \\
\hline $\mathrm{Ya}$ & $8(20)$ & $13(14,3)$ & 0,443 \\
\hline Tidak & $32(80)$ & $78(85,7)$ & \\
\hline
\end{tabular}

Studi ini menemukan bahwa durasi duduk sangat berhubungan dengan kejadian NPB $(p<0,001)$. Penemuan ini sesuai dengan penelitian di Rumah Sakit Universitas Zagazig, Nigeria. 17 Salah satu penelitian di Australia menyebutkan bahwa penyebab tersering NPB pada penelitian tersebut adalah herniated nucleus pulposus. ${ }^{5}$ Duduk lebih dari satu jam dapat meningkatkan tekanan intradiskus sehingga meningkatkan kemungkinan terjadinya herniated nucleus pulposus.19 Postur tubuh yang salah juga dapat memengaruhi kejadian NPB. Hiperesktensi aktif dari tulang punggung selama duduk dapat menambah beban kontraksi pada $M$. Multifidus, $M$. Iliocostal dan $M$. Internal oblique sehingga terjadi nyeri. Duduk berselonjor dapat membentuk dukungan tambahan dari jaringan lain sehingga beban otot untuk menanggung berat tubuh berkurang. 20 Sebuah intervensi dibutuhkan agar perawat dapat mempertahankan postur tubuh yang baik untuk mencegah NPB terjadi.

Hasil yang bertolak belakang ditemukan pada penelitian di Taiwan, yaitu NPB pada perawat lebih cenderung dipengaruhi oleh berdiri dan berjalan daripada duduk.13 Pernyataan lain adalah NPB mungkin tidak hanya terbentuk karena satu penyebab, namun dari seluruh aktivitas perawat tersebut dapat menyebabkan NPB, seperti memindahkan pasien, mendorong tempat tidur dan berdiri lama. ${ }^{17}$

Beberapa faktor risiko lain seperti jenis kelamin dan obesitas juga di analisis dalam penelitian ini. Jenis kelamin tidak menunjukkan adanya hubungan dengan kejadian NPB pada penelitian 
ini ( $p=0,211$ ). Burdoff (1997) mengulas 35 jurnal dan menemukan bahwa jenis kelamin tidak berhubungan dengan kejadian NPB. ${ }^{21,22}$ Hasil ini bertolak belakang dengan beberapa penelitian yang dilakukan di Iran dan Belanda yang mengatakan bahwa wanita cenderung mengalami NPB. ${ }^{7,23}$

Penemuan ini mungkin terjadi akibat pria tidak mau mengakui adanya nyeri karena takut dianggap lemah sehingga hasil yang didapatkan lebih rendah pada pria. Selain itu, wanita memiliki ambang rasa nyeri yang lebih rendah dari pada pria sehingga pelaporan lebih rendah terjadi pada pria. $^{21,22}$

Obesitas tidak memengaruhi NPB pada studi ini $(p=0,443)$. Hal ini sesuai dengan beberapa studi di Turki dan Belanda, namun bertolak belakang dengan studi di Taiwan. ${ }^{6,9,23}$ Penemuan ini mungkin terjadi bias mengingat proporsi perawat yang obesitas dan tidak obesitas tidak seimbang (obesitas $16 \%$; non obesitas $84 \%$ ).

Keterbatasan dari penelitian ini adalah potensi

\section{Daftar Rujukan}

1. Purnamasari $H$, Gunarso $U$, Rujito L. Overweight sebagai faktor risiko low back pain pada pasien poli saraf RSUD Prof. Dr. Margono Soekarjo Purwokerto. Mandala of Health. 2010;4(1):26-32.

2. Badan Penelitian dan Pengembangan Kesehatan. Laporan hasil riset kesehatan dasar. Jakarta. 2013.

3. Jones GW, Cowen J, Jordan JL, Uthman O, Main $\mathrm{CJ}$, Glozier $\mathrm{N}$ et al. Absence from work and return to work in people with back pain: a systematic review and meta- analysis. Occup Environ Med. 2014;71:448-456. doi:10.1136/oemed-2013- 101571.

4. The Health and Safety Executive. National statistic 2009/2010. United Kingdom. 2010.

5. Karahan A, Kav S, Abbasoglu A, Dogan N. Low back pain: prevalence and associated risk factors among hospital staff. J Adv Nurs. 2009;65(3):516- 24.

6. Lin PH. Tsai YA, Chen WC, Huang SF. Prevalence, characteristics and work-related risk factors of low back pain among

7. Rezaee M, Ghasemi M. Prevalence of low back pain among nurses: predisposing factors and role of work place violence. Trauma Mon. 2014;19(4).

8. Madawala SGML, Warnakulasuriya SSP. untuk terjadi recall bias saat perawat mengisi kuesioner yang ada. Penelitian ini hanya mengukur satu aktivitas dari perawat dan tidak mengukur aktivitas lainnya. Durasi duduk yang diukur di dalam penelitian ini adalah durasi duduk total lebih atau kurang dari 4 jam dengan diantaranya ada aktivitas lain seperti berdiri, berjalan, dan lainnya. Selain itu, jumlah sampel berdasarkan jenis kelamin juga tidak merata.

\section{Simpulan}

Terdapat hubungan yang bermakna antara durasi duduk dengan kejadian NPB pada perawat. Seringkali aktivitas yang lebih berat cenderung lebih difokuskan, sedangkan aktivitas duduk diremehkan. Namun dalam kenyataannya, aktivitas dianggap ringan ini justru menjadi salah satu alasan seorang perawat terus menerus mengalami NPB. Intervensi lebih lanjut dibutuhkan untuk mengurangi probabilitas kejadian NPB pada perawat.

Occupational health problems and associated factors among nurses working in paediatric critical care setting in a tertiary care children hospital in Colombo, Sri Lanka. Proc Annu Sci Sess Fac Med Sci. 2015.

9. Ovayolu O, Ovayolu N, Genc M, Col-Araz N. Frequency and severity of low back pain in nurses working in intensive care units and influential factors. Pak J Med Sci. 2014;30(1):70-6.

10. Curran $M$, Dankaerts $W$, O'Sullivan $P$, O'Sullivan L, O'Sullivan K. The effect of a backrest and seatpan inclination on sitting discomfort and trunk muscle activation in subjects with extension- related low back pain. Ergonomics. 2014;57(5):733-43.

11. Malik AN, Rasul HN ur, Siddiqi FA. Cross sectional survey of prevalence of low back pain in forward bend sitting posture. Rawal Med J. 2013;38(3):253-5.

12. Gupta N, Christiansen CS, Hallman DM, Korshøj M, Carneiro IG, Holtermann A. Is Objectively Measured Sitting Time Associated with Low Back Pain? A Cross-Sectional Investigation in the NOMAD study. PLOS ONE. 2015;10(3):e0121159.

13. Shieh $\mathrm{S}-\mathrm{H}$, Sung $\mathrm{F}-\mathrm{C}$, Su C-H, Tsai $\mathrm{Y}$, Hsieh VC-R. Increased low back pain risk in nurses with high workload for patient care: A questionnaire survey. Taiwan J Obstet 
Gynecol. 2016;55(4):525-9.

14. Sikiru L, Hanifa S. Prevalence and risk factors of low back pain among nurses in a typical Nigerian hospital. Afr Health Sci. 2010;10(1):26-30.

15. Sikiru L, Shmaila H. Prevalence and risk factors of low back pain among nurses in Africa: Nigerian and Ethiopian specialized hospitals survey study. East Afr J Public Health. 2009;6(1):22-5.

16. De Castro AB, Cabrera SL, Gee GC, Fujishiro $\mathrm{K}$, Tagalog EA . Occupational health and safety issues among nurses in the Philippines. AAOHN J. 2009; 57(4):149-57.

17. Abou AM, El-Najjar AR, El-Fattah NA, Hassan AA. Prevalence of low back pain in working nurses in Zagazig University Hospitals: an epidemiological study. Egyptian Rheumatology and Rehabilitation. 2014; 41(3):109-15.

18. Froud $R$, Patterson $S$, Eldridge $S$, Seale $C$, Pincus $T$, Rajendran $D$, et al. A systematic review and meta-synthesis of the impact of low back pain on people's lives. BMC Musculoskelet Disord. 2014;15:50.
19. Maha $M$, Mohamed $M$, Hanan $H$, et al. Low back pain and coping strategies' among nurses in Port Said City, Egypt. J Nurs Educ Pract. 2015;5(7):55- 62.

20. Schinkel-Ivy A, Nairn BC, Drake JDM. Investigation of trunk muscle cocontraction and its association with low back pain development during prolonged sitting. J Electromyogr Kinesiol. 2013;23(4):778-86.

21. Olivier B. Factors Associated with Low Back Pain in Hospital Employees. 2008

22. Burdorf A, Sorock G. Positive and negative evidence of risk factors for back disorders. Scand J Work Environ Health. 1997 ;23(4):24356.

23. S Han, T \& Schouten, Johannes \& E J Lean, M \& Seidell, Jaap. The prevalence of low back pain and associations with body fatness, fat distribution and height. International journal of obesity and related metabolic disorders : Journal of the International Association for the Study of Obesity. 1997 .doi:10.1038/sj.ijo.0800448 